\title{
Training of transport industry personnel in the digital economy: the evolution of information educational technology
}

\author{
Valery Khabarov ${ }^{1, *}$, and Irina Volegzhanina \\ ${ }^{1}$ Siberian Transport University, 630049, Novosibirsk, Russia, Dusi Kovalchuk st., 191
}

\begin{abstract}
The urgency of the study is stipulated by the problem of professional training of personnel for the leading industries of the material production of the Russian Federation, one of which is the transport industry, in the context of implementation of the digital economy program and the integrated scientific and technological project "Digital Railway". The nature of knowledge belonging to the intellectual field of the industry is revealed through the synthesis of the humanitarian (associated with man) and formal logical (associated with artificial systems). New requirements make it necessary to refer to modern educational technologies in the elearning paradigm 3.0. Such technologies are based on knowledge presented in accordance with the international standard ISO/IEC - in the ontology format. In this regard, this paper is aimed at revealing the possibilities of semantic technologies in the development of virtual learning environments for educational organizations in the network structure of sectoral subordination in the open projects model. Development of ontological content is carried out remotely by joint efforts of representatives of the employer and education. FSBEI of Higher Education "Siberian State Transport University" (Novosibirsk) implements an interuniversity project on the development of the multilingual electronic learning environment "Onto.plus" on the basis of new technologies in the format of the digital economy. The proposed educational solution has been tested in the real learning process. Its effectiveness has been proved for the training of future transport industry personnel; the directions of the project development are outlined.
\end{abstract}

\section{Introduction}

The adoption of the Federal program for the development of the economy of the new technological generation "Digital Economy of the Russian Federation" (Order of the Government of the Russian Federation of July 28, 2017 No. 1632-r.) marked the beginning of a number of initiatives of high-tech industries of material production, which include the transport industry. Thus, as a part of the program of innovative development of JSC "Russian Railways" for the period 2016-2020, a comprehensive scientific and technical project "Digital Railway" is approved. This project conforms to the leading idea of the

\footnotetext{
* Corresponding author: khabarov51@mail.ru
} 
digital economy, which consists in the creation of hybrid corporate intellects to exclude the negative influences of the human factor in the relations between subjects of economic activity. This becomes possible because of modern digital technologies, many of which are based on knowledge in the form of logical judgments.

Knowledge is an important intangible asset that determines the market value of an industry corporation whose activities are strictly regulated, as well as a growth driver in the digital economy. It should be noted that JSC "RZD" declares knowledge management as a promising strategy for its innovative development. The appeal to this management concept causes a change in the paradigm of corporate informatization in the form of a transition from information systems to information management systems that allow interactions in a hybrid corporate environment based on explicit (formalized) and implicit (personal) knowledge. Knowledge is redistributed between artificial and natural corporate agents, regulates their relationship with each other and with the external environment. This requires the formalization of industry regulations and the creation of knowledge bases.

All of the above defines new requirements for the labor resource of the industry. According to the employer, the implementation of the project "Digital Railway" will change the composition of job positions and the content of professional activity in railway transport. Hence, the creation of tools for the effective interaction of education, science, and industry for the formation of competencies, which are in demand in the digital economy, is becoming an urgent scientific problem. Virtual learning environment (VLE) based on semantic technologies can be considered as one of them.

It should be noted that by now, there are already prerequisites for the emergence of such VLE for the network of educational organizations of railway transport. The first group of prerequisites (socio-economic) is formed by the necessary and possible conditions for the development of network learning resources of industry specialization. Let's list these prerequisites by answering two questions:

Why is it necessary?

1. Orientation to the development of national universities by the model "University 3.0 ", in which the educational organization is considered as a global player in the knowledge market, as the center of not only science and education, but also entrepreneurship.

2. Lack of finance to maintain geographically closed educational organizations in the network structure of sectoral subordination. One of the items in the budget expenditures is the expansion and updating of the learning resources base.

3. The need to standardize educational programs and content of learning resources, while it is important to take into account the professional standards and requirements of the employer (industry) to the quality of graduate training.

4. Awareness of the fact that knowledge is an intangible asset separated by industry and a network of educational organizations of sectoral subordination.

Why is it possible?

1. The centralized management of sectoral educational organizations. So, under the jurisdiction of the Federal Agency for Railway Transport (Roszheldor), there are universities, their branches, specialized secondary educational institutions of vocational education, and the educational and methodological center for education in railway transport.

2. Territorial distribution and lack of internal competition between the educational organizations of the network, which determines their interest in creating a single educational resource.

3. The existence of modern international standards and information technologies that allow creating open network resources: technologies and standards of Internet 2.0, semantic 
web technologies, and standards of knowledge representation in the Internet of the new generation 3.0.

4. Availability of technical capabilities to organize cloud resources (rental of dedicated servers and organization of information and knowledge stores on them).

\section{The evolution of information educational technology}

Information technology has a direct impact not only on the development and globalization of national economies, but also on education, in such a way erasing digital barriers, developing international knowledge-oriented networks that unite universities and research centers in developed and developing countries. Let's consider the basic stages of the development of information educational technology, which will be called virtual learning environments (VLE), following the terminology of the InterLabs Research Institute of Bradley University (USA) [5]. Conventionally, we can distinguish five stages of the evolution of the VLE and, correspondingly, five generations of such environments.

The VLE of the first generation existed until 1991. To organize the learning process, a set of disparate tools was used to build simple online courses (e-mail; programs that allow you to quickly exchange messages; tools for organizing files and storing them, etc.). The form of presentation of digital learning content was similar to printed linear texts. The drawbacks of the VLE of the first-generation, which did not allow going beyond the traditional approach in organizing the learning process, include the lack of interrelation between their components and the form of presentation of learning content. Learning content in the VLE of the first generation is an electronic version of written textbooks in a natural language. They are traditional and, undoubtedly, dominant non-verbal form of knowledge representation in teaching. They are distinguished by linguists into an independent type of texts, which is represented by textbooks, teaching aids, methodological manuals, and encyclopedias.

The VLE of the second generation appeared after 1991. They use software tools for organizing distance learning, which provide ample opportunities for developers and students. Among such functions are: administration of the learning process; creation and support of learning content; automation of learning outcomes control; formation of electronic portfolios of students, etc. Unlike the VLE of the first generation, the VLE of the second generation allows individualization of the learning process based on user information stored in the database. Also, the form of presentation of learning content has changed. It became hypertext. This form of representation of knowledge is not fundamentally new; it existed even before the advent of the Internet. It's about texts that are not read consistently from beginning to end. These are, for example, directories, catalogs, encyclopedias, instructions, etc.

The VLE of the second generation has qualitatively improved the process of distance learning, which acquires a mass character. It is at this stage that open universities appear. However, the VLE of the second generation also has its drawbacks due to the lack of opportunities for effective user interaction, virtualization tools and intellectualization of the learning process, tools for collective development of courses, etc. The problem of effective navigation in the hypertext information space has been actualized, since hypertext is an internally weakly structured form of knowledge representation. Therefore, like the VLE of the first generation, the VLE of the second generation did not fundamentally change the traditional educational paradigm. They were replaced by the VLE of the third generation, which now dominate the educational services market. They have all the technical capabilities of the VLE of the second generation, but they also have additional capabilities: a) tools that allow the addition of multimedia (images, audio and video files, etc.); b) multiuser server solutions for audio and video conferencing, simultaneous use of one network 
application or document, etc.; c) the ability for users' communication through questionanswer systems (for example, forums, chat rooms, etc.). Unlike the VLE of the first and second generations, the VLE of the third generation introduces a role model of the learning process and a full information and communication space. The disadvantages of these VLEs are related to the form of content presentation, which has not changed fundamentally and has remained hypertext.

The reason for the development of the VLE of the fourth generation is the active development of globalization and the emergence of a new socially-oriented educational paradigm, which was named education 2.0. The focus now is not the teacher who manages the local learning resource, but the student and the global learning resources. As a result, elearning appears in its modern presentation. The VLE of the fourth generation has all the technical capabilities of the VLE of the third generation, but a fundamentally different form of presentation of learning content. This is a semantic network that allows a) the automation of the learning process with the use of intelligent agents and $b$ ) the individualization of the learning process, where the teacher plays the role of a mentor who, taking into account the personal and individual typological characteristics of the student, builds his educational trajectory and creates conditions for effective learning.

Considering the perspective of the development of virtual learning environments, we can talk about the creation of the VLE of the fifth generation, which allows personalizing the learning process. Personalization of learning in the VLE of the fifth generation is carried out by intelligent support of this process through content, which requires the creation of an intelligent system based on knowledge. In this case, the form of representation of knowledge should be clear to both the student (person) and the computer (machine). Such a form is ontology, which is acknowledged by ISO as a modern international standard of knowledge representation in e-learning [6]. Ontologies are at the heart of semantic web technologies (or Web 3.0) - part of the global concept of Internet development. A lot of psychological, pedagogical, and methodical researches are devoted to knowledge. However, only some authors point out the relationship between the two aspects of the nature of knowledge that are manifested in the hybrid environment of the modern world - the "anthropomorphic" (human-oriented, dominant in the humanities) and formal logical (oriented to artificial intelligence systems dominating in computer science) [4]. Another aspect of knowledge is determined by their belonging to the intelligent field of the industry. Some foreign authors indicate the industry related knowledge [5; 7]. This allows expanding the concept of "knowledge" and proposing the following working definition:

Knowledge is an information object that has an ordered form that exists in some environment called intelligence. Both a natural agent (person) and an artificial agent can have intelligence. Since an agent is an active entity with a purpose, knowledge is the main resource for achieving it. If the agent is a student, then he is able to generate new knowledge on the basis of already existing knowledge both independently and under the control influence, including using digital technologies, which involves the presentation of knowledge in the form of logical judgments that enable the implementation of the mechanism for their processing and reuse.

Knowledge belonging to the intelligent field of the industry can be defined as industry knowledge. This is the entirety of knowledge circulating in a certain industry of the economy, reflecting the specifics of the activities of organizations related to this industry, and continuously forming in the system "production - science - education" at the stages of the integrated life cycle. They include the knowledge used in the learning process on the basis of educational organizations of industry specialization, having all the characteristics of industry knowledge, but at the same time, adapted for better digestion of knowledge by students [2]. 
This understanding of knowledge forms benchmarks for the selection and presentation of meaningful educational information in e-learning resources, the choice of technologies for the development of didactic tools, forms, and methods of learning. This determined the purpose of the study - to offer a modern educational solution for the formation of perspective competencies of transport industry personnel in the interaction of education, science, and production. To achieve this goal, the following problems are solved in the paper: 1) to specify the competences of future transport workers that ensure the effectiveness of professional activity in the digital economy; 2) justify the choice of technologies for the development of educational solutions; 3) describe the main results of the project on the development of the VLE for the network of railway universities in Russia based on technologies of digital economy.

\section{Materials and methods}

The study was carried out by the team of the scientific research laboratory "Information technologies of transport" of the faculty "Business Informatics" with the participation of the representatives of the departments "Foreign Languages" and "Russian Language and Oriental Languages" of the FSBEI of Higher Education "Siberian State Transport University" (SSTU, Novosibirsk) as a part of the grant of FSBEI "Training and Methodology Center for Railway Transport”, Moscow. Gov. contract №30/16 (165-16) dated May 30, 2016 for developing software for a multilingual learning resource in the form of a Russian-English-Chinese subject ontology using semantic web technologies. As a source of knowledge for the pilot module of the resource, educational materials providing discipline "General course of railways" were selected, which is compulsory for students of all areas and specialties in railway universities.

In the course of the study, the following methods were used together:

- theoretical analysis: the study of philosophical, psychological, pedagogical, methodological, economic, and technical literature, normative and legal and program documents in the field of education and transport, generalization of world experience in the development of similar educational products, modeling;

- praximetric: examination of the software prototype, registration of the computer program and e-learning resources, analysis of the results of the educational and research activities of the students;

- survey and diagnostic: questioning, interviewing, testing;

- observational: observation (direct, indirect, included, introspection) of the process of developing ontological content; of the course of experimental training;

- experimental training;

- methods of data processing and systematization: statistical methods $(\chi 2$ criterion, Student's t-test for comparing average values, correlation and regression analysis using the Pearson pair correlation coefficient), ranking, scaling, graphical representation of data.

Experimental training was conducted on the basis of FSBEI HE SSTU in 2016-2018. The experimental and control groups included 20 teachers and 218 students.

\section{Results}

More than 100 sources (strategic documents of the Government of the Russian Federation, the sphere of education, JSC "RZD"; publications in the media; scientific publications) were analyzed to specify the planned learning outcomes. A semantic core was identified among them in the form of a list of concepts that formed the basis for a semantic model (ontology) that allows the representation of interrelation between knowledge, skills, and 
competences ensuring efficiency of professional activity of a graduate of the transport university in the digital economy. As a result, it was concluded that all the competencies allocated in the model assume the ability of any employee in any position to perform the necessary actions to achieve the stated goal on the basis of knowledge. Hence, in the absence of the ability to manage knowledge, a graduate cannot implement professional activity within the established norm.

An employee who is able to manage knowledge (explicit and implicit) is also able to contribute to the innovative development of the industry and the realization of its social mission. This ability determines career development in the industry from a simple reflexive model of knowledge management (work position) to a semantically intense activity of a creative nature (designing intelligent transport systems, etc.). In addition, a well-organized interaction of the employee with other agents in the business process ensures the comfort of his stay in the corporate environment and the desire to remain in the industry throughout his working life. Hence, there is a need to revise the established approaches in training the industry personnel. The transfer of finished knowledge becomes insufficient; work with semantics of knowledge and mastering of knowledge management technologies acquire value.

In the context of the evolution of the VLE, a promising solution is the appeal to the international standard for the representation of knowledge in ontology format and semantic web technologies (Semantic Web). In the most general sense, ontology is a compact form of knowledge representation in the form of semantic links that allows interoperability of knowledge in various areas of human activity in different national languages. For the "education - science - production" system, the potential of ontologies is revealed in its following properties: 1) ensuring the unity of understanding of the meaning (semantics) of objects and the relationships connecting them within the framework of one subject area / process; 2) the ability to be perceived by both natural and artificial intelligent agents; 3 ) the possibility to produce computer processing of knowledge based on it; 4) the possibility to reuse the knowledge stored in databases of information systems; 5) the ability to reflect the conceptual basis of the organization of human memory in the form of frames, which can reduce the learning time and deepen acquisition of knowledge; 6) the possibility of integrating newly created ontologies with ontologies already existing in the world through the standard ontology language (Web Ontology Language, OWL) for the formation of open network resources (scientific, educational, industry, complex); 7) the possibility to translate into any natural languages to create multilingual educational resources, since knowledge after separation from its carrier and formalization depends little on the specifics of the national language, i.e. translation is carried out at the level of concepts and attitudes; multilingual ontologies can be used in the process of learning foreign languages to form equivalent terminology for students.

On the basis of semantic web technologies, a prototype of the multilingual e-learning environment (MELE) was developed, called "Onto.plus". This is a complex tool for the joint development of learning content based on the "onto-wiki" model in a remote format by representatives of the employer (JSC "RZD") and a network of railway universities, which is provided by a set of methodological and program solutions. Let's consider them further. In order to create ontological content by Russian-speaking authors who are not familiar with programming and ontology editors, a variant of the controlled (limited) Russian language (CRL) was proposed. It brings together an understandable and convenient for the person way of expressing thoughts with the language of ontologies understandable for the computer. A special methodology explains to the authors the features and rules for the representation of knowledge on the proposed version of the CRL. Since the development of multilingual content requires the existence of versions in several natural 
languages equivalently aligned between each other, an additional methodology was developed for translation and described in an earlier paper [8].

To support the proposed method of knowledge representation, a prototype of the multiuser ontology editor built into the MELE "Onto.plus" was developed. This editor supports the standards of the Semantic Web and is implemented on a web platform, allowing synchronous work of several authors and compilers on one ontology. In its framework, a language for describing ontologies, which is close to the natural language, is formed, and ontologies are exported and imported in standard formats (owl, rdf). It is advisable to add the text files, images, video, and hyperlinks to the Internet resources to the ontology concepts. The authors can see the results of their work in a special view mode.

In addition to such didactically useful features as multilingual, multimedia, terminological vocabulary, and ontology visualization in the form of a graph, the potential of the editor "Onto.plus" makes it possible to realize automatic generation of tests. The ontology in the form of owl as a model of learning space (composition of multiscale ontologies) opens wide prospects for using the mechanisms of inference, many of which are freely available (FaCT ++, HeriT, Ontop, Pellet, ELK, jcel). They allow, among other things, generating tests to verify the achievements of students. More flexible algorithms for testing can be created by using artificial intelligence technologies. As an example, we call Prolog, which has great opportunities for working with the ontology graph. The testing procedure in MELE "Onto.plus" is based on the idea of experiment planning, when the vulnerable fragments in the student's knowledge system are searched. The number of test tasks is determined by the size of the ontology. The order of their presentation to the user depends on the chosen strategy. It assumes two main strategies - "width-first traversal of a graph" and "depth-first traversal of a graph". The strategy of the width-first traversal of an ontology graph is suitable for testing knowledge throughout the training course. To check more specific knowledge, the graph can be traversed by individual branches "in depth". It is also possible to use mixed strategies.

To ensure a unified understanding of the matter of ontological content creation, a sequence diagram was constructed for the following role models (roles) involved in the process: compiler of texts in a controlled natural language (CRL); content editor; knowledge engineer responsible for the implementation of the text in the software environment; translator; software environment.

Using the developed tools, a prototype of the MELE "Onto.plus" was created, in which the aligned between each other versions of the ontology "General course of railways" in several national languages (with breakdown by thematic modules) are posted. The basic version is the ontology in Russian. Ontologies in English are intended for interoperability with the worldwide learning resources. They serve as an intermediary in the training of foreign students and can be used in the process of learning professionally oriented English language. To check the effectiveness of the proposed educational solution in the formation of competencies related to the ability of future transport personnel to manage knowledge in the digital economy, experimental training was organized, which was carried out in several stages on the basis of the FSBEI HE SSTU. Methodological support of this process was developed, participants (teachers and students) were instructed, and their methodological, technical and psychological support was organized.

The initial stage of the experiment (2016) was associated with the ascertaining of actual level of the formation of components in the structure of students' ability to manage knowledge (motivational and personal, resource and evaluative, functional and activity). Four hierarchical levels of such ability as integrative whole were singled out: critical, threshold, sufficient, and high. Their content and evaluation procedure are described in [1]. The obtained data showed that the "resource and evaluation" and "functional and activity" components were at a critical level (more than $80 \%$ and about $50 \%$, respectively) for most 
examinees (98 in total). "Motivational and personal" component, according to the subjective assessment of students, was formed at the high (42.86\%) and sufficient $(51.02 \%)$ levels. The results of the correlation-regression analysis using the Pearson pair correlation coefficient made it possible to establish a medium strength of the connection between the knowledge and skills of students and the weak strength of the connection between the selfassessment and the actual level of the formation of the "functional and activity" component. The detailed ascertaining experiment is described in [9].

The next stage of experimental training was associated with the successive introduction of several factors: the methodology for the development of cognitive skills of students on the basis of ontologies, MELE "Onto.plus", and the professional development of teachers. The results of the three control segments are summarized in Table 1, from which it can be seen that the students of both groups have progress in developing the ability to manage knowledge. However, it is more pronounced and shows greater stability in the experimental group. In the course of the training, it was also found that the relationship between the components of respondents' ability to manage knowledge is strengthened.

Table 1. Dynamics in the experimental and control groups of students at the stage of the formative experiment (68 people, SSTU, 2017).

\begin{tabular}{|c|c|c|c|c|c|c|}
\hline Group & \multicolumn{3}{|c|}{ Experimental (\% of students) } & \multicolumn{3}{c|}{ Control (\% of students) } \\
\hline Level & Segment 1 & Segment 2 & Segment 3 & Segment 1 & Segment 2 & Segment 3 \\
\hline high & $0,00 \%$ & $0,00 \%$ & $12,12 \%$ & $0,00 \%$ & $0,00 \%$ & $0,00 \%$ \\
\hline sufficient & $9,38 \%$ & $15,63 \%$ & $33,33 \%$ & $5,56 \%$ & $5,56 \%$ & $16,67 \%$ \\
\hline threshold & $31,25 \%$ & $46,88 \%$ & $33,33 \%$ & $13,89 \%$ & $33,33 \%$ & $25,00 \%$ \\
\hline critical & $59,38 \%$ & $37,50 \%$ & $21,21 \%$ & $80,56 \%$ & $61,11 \%$ & $58,33 \%$ \\
\hline
\end{tabular}

The final stage of the experimental training was devoted to a comprehensive verification of the innovation after the elimination of the remarks revealed in the second stage. Figure 3 shows the results of the final experiment for the control (CG1) and experimental (EG1) groups, where the upper-case letters indicate the levels of readiness: $\mathrm{H}$ - high, $\mathrm{S}$ - sufficient, $\mathrm{T}$ - threshold, C - critical.

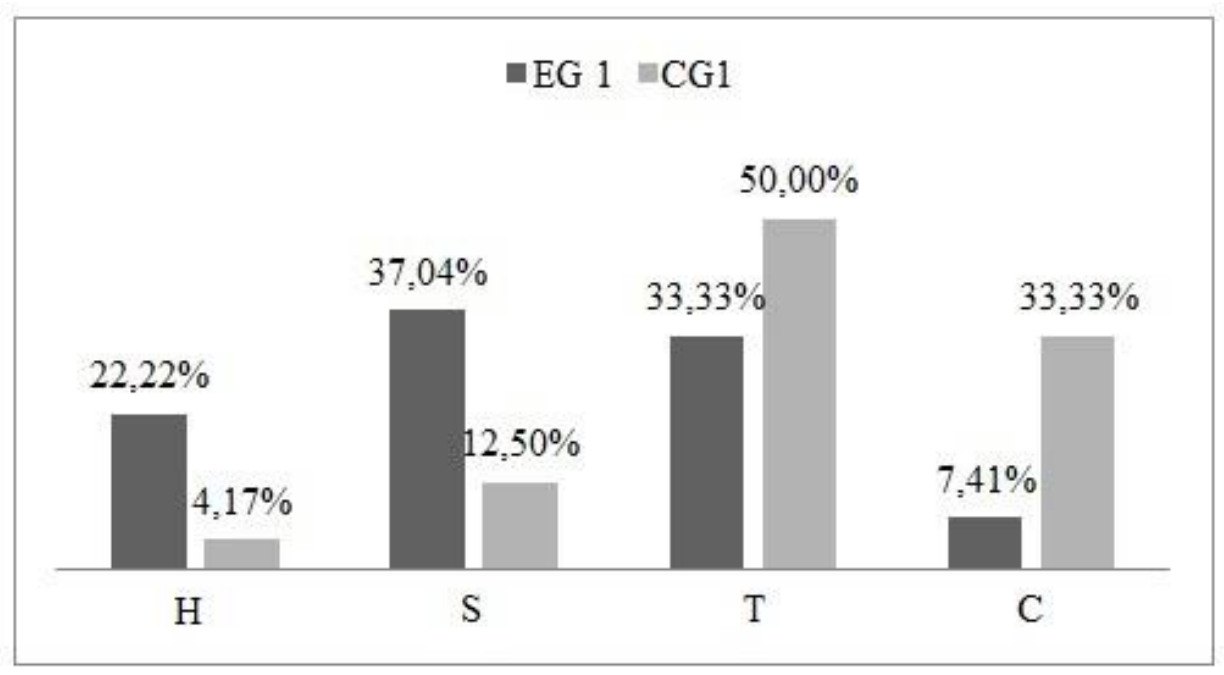

Fig. 3. Distribution of students in the experimental and control groups according to the levels of readiness for knowledge management (52 people, SSTU, 2017-2018). 


\section{Discussion of results}

The results obtained during the experimental training prove the effectiveness of MELE "Onto.plus" for forming the competencies of future transport workers on the basis of their ability to manage knowledge. The findings of the ascertaining experiment indicate a lack of effectiveness of traditional didactic tools (the components of the ability to manage knowledge are related superficially). Further observations showed that the strength of the connection between them was strengthened in students of the experimental group. At the second stage of the experiment, it was characterized as a "noticeable positive", and at the final stage - as "strong". The number of students with a critical level of ability to manage knowledge gradually decreased, the number of students with a threshold and sufficient levels increased, and students with a high level of such ability appeared. The final check confirmed the stability of the fixed changes.

The uniqueness of the proposed educational solution is determined by its consistency with the nature of hybrid corporate environments, which manifests itself in the orientation to work with explicit and implicit educational knowledge belonging to the intelligent field of the transport industry, with the interaction of education, science, and production. Work with explicit (formalized) knowledge is carried out using technologies of the digital economy format (semantic web technologies) with the joint development of ontological content in the MELE editor. Work with the implicit knowledge of students, which are the basis of competences that ensure the effectiveness of their professional activities in the digital economy, is carried out in the learning process through special methodologies, technologies, resources, construction of an individual trajectory of acquisition of knowledge on the basis of intelligent testing, etc.

The development of the project "Onto.plus" is seen in several interrelated directions:

- development of software related to the implementation of the description of logical constructions; inference engine within the application; expert system on the basis of ontologies and machine output; possibilities of the proposed variant of the ontology description language; variable relations between classes of objects; meta knowledge that defines the classification of relations and objects; annotation tools;

- organization of interaction of representatives of education, science, and production in the creation and actualization of the content of MELE "Onto.plus";

- introduction of developments in the process of professional training of future transport workers on the basis of a network of specialized higher education institutions.

\section{Conclusions}

Understanding the future organizational and technological changes in Russia and its leading industries of material production, which include transport, makes us think about what competencies should be formed in future transport workers, how to build effective interaction between education, science, and production. For JSC "Russian Railways" as an industry corporation at the level of managerial maturity, the effectiveness of the professional activity of young employees - graduates of transport universities in a hybrid corporate environment is provided by their ability to manage explicit and implicit knowledge using modern information technologies. The result is the implementation of the normative model of job behavior on the basis of an array of constantly updated regulatory documents.

Knowledge, which belongs to the intellectual field of the industry, whose multidimensional nature is manifested in the hybrid world of the digital economy as a synthesis of humanitarian and formal, becomes the most important asset of the corporation. In this regard, the process of corporate informatization is completely different. It is 
implemented through the system of intelligent agents, which involves the formalization of industry regulations in the form of rules, instructions in the ontological form (knowledge base). This will require the employees in all positions to have new competencies. Along with the process approach, it will be necessary to possess knowledge management technologies, knowledge engineering, etc. Hence, it becomes possible to predict changes in the composition of job positions in the transport industry as the "Digital Railway" project is implemented. Presumably, the "homeostatic" professions associated with the operation of transport infrastructure facilities can become in-demand; "creative" professions focused on the creation of new facilities and technologies; "system analysts" that perform analysis and description of subject areas/business processes, the formulation and formalization of tasks.

It should be noted that there is a serious technological reserve in the FSBEI HE SSTU, which should be evaluated in the context of the implementation of the "Digital Railway" project. The practical significance of the results of the proposed educational solution is to create the VLE based on semantic technologies that allow the interaction of education, science, and production to form competencies for future transport workers in digital economy (State registration of the computer program № 2017618577 of 04.08.2017). In particular, the following are developed:

- a prototype MELE "Onto.plus", the content of which is presented in the form of ontologies;

- a multi-user ontology editor, which allows the joint creation of content in accordance with the international standard knowledge representation ISO/IEC in a variety of natural languages;

- scientific and methodological support for the interaction of education, science, and production, contributing to the effectiveness of the learning process using the MELE "Onto.plus" and including the methodology for developing content in the multi-user ontology editor on the onto-wiki model; methodology for the development of cognitive skills of students on the basis of ontologies; methodological instructions intended for developers of learning content and participants in the learning process; materials for the diagnosis of the ability of students to manage knowledge; a program of professional development for teachers.

The availability of a methodological basis for the development of ontological content is a prerequisite for the development of the project as an open one, to which the employer and industry universities are connected. Communication is two-way, since an open project involves not only the sharing of a network resource, but also its joint formation and actualization. It is important to understand that the VLE of the generation of e-learning 3.0 does not abolish hypertext learning environments, but can integrate with them and expand the possibilities of distance learning.

\section{References}

1. I.S. Volegzhanina, Continuous professional education: theory and practice: the collection of articles on the materials of the IX International Scientific and Practical Conference of Teachers, PhD and students, Novosibirsk: SAFB, 81-85 (2018)

2. I.V. Mitsuk, V.I. Khabarov, I.S. Volegzhanina, Educational Technology and Society 19-3, 473-491 (2016) http://ifets.ieee.org/russian/depository/v19_i3/pdf/9.pdf

3. A.I. Subetto, Theory of the fundamentalisation of education and universal competences (noospheric paradigm of universalism), Scientific monographic trilogy (Asterion, SPb, 2010)

4. V.I. Khabarov, Economics of railways 10, 56-66 (2009) 
5. J. Edler, Knowledge Management in German Industry. Study in the Framework of an OECD Initiative of the Centre for Educational Research and Innovation (CERI) on behalf of the Donors' Association for the Advancement of Science in Germany with the support of the Federal Ministry for Education and Research, Final report (Fraunhofer Institute for Systems and Innovation Research (ISI), Karlsruhe, 2003)

6. ISO/IEC 20016-1:2014 Information technology for learning, education and train-ing Language accessibility and human interface equivalencies (HIEs) in e-learning applications, Part 1: Framework and reference model for semantic interoperability

7. C.P. Pathirage, R.D.G. Amaratunga, R.P. Haigh, The role of tacit knowledge in the construction industry: towards a definition, CIB W89 Int. Conf. on Building Education and research (BEAR) (2008)

8. I.S. Volegzhanina, Russian Linguistic Bulletin 4(8), 93-95 (2016)

9. I.S.Volegzhanina, S.V. Chusovlyanova, V.A. Adol'f, E.S. Bykadorova, E.N. Belova, Journal of Social Studies Education Research 8, 39-61(2017) 